\title{
n-Logue: The Story of a Rural Service Provider in India
}

\author{
Ashok Jhunjhunwala \\ Dept. of Electrical Engineering, Indian Institute of Technology, Chennai, India \\ < ashok@tenet.res.in >
}

Anuradha Ramachandran

TeNet, India < anuradha@tenet.res.in >

Alankar Bandyopadhyay

TeNet, India < alankar@tenet.res.in >

\section{Introduction}

Can rural Information Communication Technologies (ICTs) be an effective tool to bridge the digital divide? How can the Internet help developing nations and their disadvantaged in particular? Those who lobby in favour of rural ICT believe that the Internet is not just a means of communication but is also an enabler of livelihood in rural areas and therefore, power.

For a very long time now, the developing world has carried the burden of colonization and slavery. This has resulted in a lack of confidence among developing economies and the belief that they are not at par with the rest of the world. The lack of 'access' has curtailed their ability to compete. In fact, ingenuity and hard work has not been adequate for one to enjoy economic and social benefit. In order to acquire these benefits, access to resources like education, health and employment become critical.

The Internet has been a boon in this regard. Today, one can be in the remotest corner of the world and as long as there is access to Internet enjoy access to education, health and resources. This allows them to compete and use their ingenuity and hard work to bring about a significant difference to their lives.

This paper concentrates on how ICT can affect the lives of rural people in the developing world. The total rural population of the developing world is about 3.5 billion, with their average per capita income being no more than $\$ 200$ per year. India, with 700 million rural people located in 600,000 villages, is a reflection of the developing world. The key issue that is addressed in the paper is whether technology can bring about a difference in the lives of people who earn less than half a dollar a day. Can health and education be made available to them? Can they afford the Internet? And ultimately, can it significantly enhance their livelihoods and income?

\section{The ICT Delivery Model}

As mentioned earlier, India has over 700 million people living in over 600,000 villages. Therefore any program that is implemented in 100,1,000 or 10,000 villages is miniscule and makes very little difference to the entire rural economy of India. The underlying element here is that a program should have the potential to scale to half a million plus villages. Anything that is not scalable is simply an experiment, probably worth watching, but not of significant relevance.

There are three factors that are mandatory to build a scalable and successful business in rural areas. These are: 
- Technology that is cost effective, affordable, robust, scalable and capable of delivering the relevant applications

- A clear business model that addresses all market, stakeholder and operational needs

- An organisation that is exclusively focussed on the rural market, which thinks and acts rural

\section{Connectivity}

Over the last 15 years, the state owned incumbent telecom operator, BSNL, has taken fibre to almost every taluka (county town) in India. These fibre lines are infinite bandwidth pipes. Further, if a wireless coverage of 15 to $20 \mathrm{~km}$ is established from these county towns, one can cover almost all villages of India. In India, a taluka typically has 300-500 villages and most of them fall within a $30 \mathrm{~km}$ radius. What is even better is that wireless technology is constantly evolving - costs are coming down and bit rates are going up. In other words, technology is present to carry this task forward.

The corDECT technology, jointly developed by TeNeT (Telecommunications and Computer Networks Group of IIT Madras) and Midas Communication Technologies Pvt. Ltd, has proved to be a major breakthrough for the cause. An exchange and a base station are installed at the taluka or county where fibre is located. This exchange functions at a temperature of 55 degree centigrade, and does not require air conditioning. The total power requirement is $1 \mathrm{KW}$. This capability counters the problem of lack of power in small towns of India. Also, in a situation when power in unavailable, a one KM generator can be easily obtained and used as a backup. CorDECT is capable of offering simultaneous voice and Internet access and can deliver 35/70kbps connectivity to villages that are within a radius of $25 \mathrm{~km}$ from the fibre-connected taluka.

The start-up cost for this technology is low. Last year, \$200 million worth of this technology was sold and deployed in India and other developing nations including Brazil, Argentina, Nigeria, Tunisia, South Africa and Singapore. An upgrade of this technology will be launched soon. The next generation corDECT technology, which will be released in the latter part of the year, aims to deliver 80/150kbps-sustained rate on each Internet connection.

Such wireless technologies work wonders for 85 per cent of the villages of India, which lie predominantly in the flat areas. In case of rough terrain, primarily mountainous regions and forests, fibre fails to go deep and the problem gets complicated. The TeNeT group is working on a solution that combines satellite and terrestrial wireless to provide low cost connectivity even in such villages. Hence, technology is not a serious issue.

\section{Business Model}

However, technology is only the first leg. The second leg is a business model, which allows this kind of set-up to scale up to $6,00,000$ villages. The issue that needs to be addressed is in villages where affordability is low, is can a business scale? Telecom operators have declared rural connectivity an unviable business.

The clue to a successful business comes from what was done in the mid 80's in India. During that time, urban area telephony was very difficult. People had to endure a 7-8 year waiting period to acquire a telephone connection. This was particularly difficult on the lower middle class and poor people.

At that time, an innovative idea was developed - find a shop in every street in an urban area and convert it into an operator-assisted telephone booth or a PCO. The PCOs were set up at street corners at a distance of about 50 metres from the closest residential areas and were manned by an operator who kept it open for 16 hrs a day, 365 days a year. The presence of these PCOs addressed the issue of distance and no one was required to undertake a long journey to avail of their services. Such PCOs spread rapidly. The approach made connectivity viable and pervasive while it also created a stream of entrepreneurs. The success of the PCO revolution can be gauged by the fact that until recently, 25 per cent of India's telecomm 
income came from these PCOs. Today, 300 million people who do not have a telephone in their house, use these PCOs. The lessons learnt from the PCO revolution were several - aggregation of demand, presence of entrepreneur-driven business, proximity to a facility for greater access.

These three factors provide the basis of a viable business model for rural ICT. Demand aggregation would address issues of affordability, while the entrepreneur and the easy access would ensure a steady stream of users.

\section{Organisation}

This leads us to the third leg - an organisation called n-logue, a rural service provider whose entire focus is rural India. It focuses on providing commercial telephone and Internet connection to every village. The company is prohibited from operating in urban areas by virtue of its charter.

n-Logue decided to adopt the demand aggregation approach to small villages by creating an Internet kiosk with a computer, an Internet connection, a printer and some accessories like web/digital camera in each village. The kiosk was to be the hub of the rural connectivity providing communication services (email, chat, browsing), as well as other much-needed applications like education and training, healthcare, agriculture consultancy and e-governance.

The kiosk operator (KO) is a rural entrepreneur and the interface with the rural customers. n-Logue chooses an enterprising local person from the village itself to setup and run the kiosk. The kiosk operator is trained to use, and to help other people use various applications, which are made available by n-Logue. The KOs are typically youngsters, mostly women, who have passed their 10th standard. They are not required to have any prior knowledge of computers.

It takes about $\$ 1000$ to set up an Internet kiosk inclusive of a wall set to receive signals, a PC with a 15" colour monitor, peripherals including speaker, microphone, CD-ROM, digital camera, inkjet printer and sound card, power back-up, cabling and an application suite consisting of word-processing, browsing and email software all in the local language as well as English.

The kiosk operator is funded through bank loans to a maximum in the range of $\$ 700$ to $\$ 800$. The kiosk needs to earn about $\$ 70$ to $\$ 80$ per month to break even, which in a village of about 1000 people roughly translates to just 7 to 8 cents per person per month. At this price level, the service becomes affordable to the rural populace and a sustainable business is built.

The next issue that needs to be addressed is who services the kiosk operator? What happens when the computer encounters a virus? Where are the technicians who are equipped to deal with such problems? Such bottlenecks would need to be addressed immediately. Also, kiosk operators would need regular support in terms of maintenance, connectivity and handling of other local issues. It was therefore decided that a middle tier of Local Service Providers (LSPs) would be created to service the needs of the kiosk operators in every county or taluka. The LSP is located in a town not more than 15 to $20 \mathrm{~km}$ from each village. This proximity enables the LSP to reach a kiosk in about 60 to 90 minutes in case of an emergency. The LSP covers a $30 \mathrm{~km}$ radius, $3000 \mathrm{sq}-\mathrm{km} / 400-600$ connections and is stationed in the place where the tower/access centre is located. The LSP is made a 50 percent partner in the total business by n-Logue. The LSP is also assigned the task of identifying an appropriate entrepreneur in the village and is required to help them, train them, and commission and maintain the equipment. What is notable here is that as long as the kiosks are not up and running, the LSP makes no money.

n-Logue, on the other hand, provides the connectivity backbone in the operations, co-ordinates with multiple technology providers for relevant applications and content, trains LSPs and kiosk operators, sources critical supplies for kiosks including the available hardware and software, co-ordinates with regulators and policymakers to ensure service availability and markets the services to the community with the help of the LSPs and kiosk operators. 
n-Logue, thus, adopts a three-tier model for rural connectivity. Tier I is the kiosk operator in the village who does the primary customer interface. Tier II is the LSP who is located at the district level. Tier III is n-Logue. The KO is integral to the entire operation. If he/she doesn't succeed, the other tiers don't succeed. While the LSP ensures that the KO succeeds, n-Logue guarantees the LSP functions.

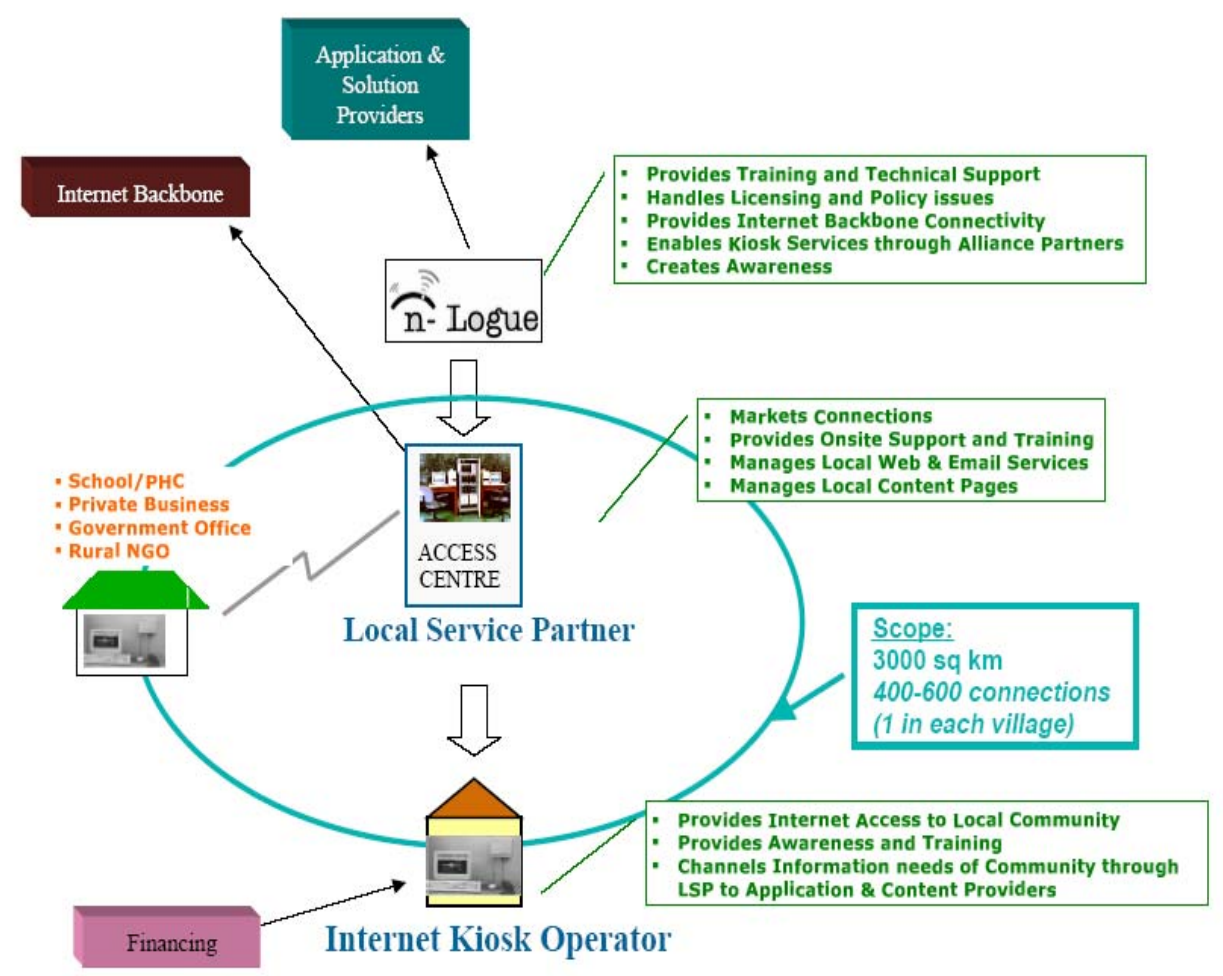

\section{Services}

\section{Communication:}

While telephony is a technology most people comprehend, e-mail and video mail are being offered by the kiosks as additional means of communication, primarily for the purpose of being in constant touch with relatives/friends living abroad or in far away places. Video mail is more popular in the rural areas since the villagers feel more comfortable with a face-to-face dialogue. These technologies are also affordable and n-logue with the aid of TeNeT has created some relevant technologies which function at low bit rates.

\section{Education:}

Education is one of the key applications that is very important to the rural populace. The education module created by nLogue is based on computer-based education and computer education.

Computer Education: n-logue has helped create a number of customized courses under the brand name of Chiraag (Fig 1) to train people to use computers. Titled Red, Blue and Green, these courses are designed for different ages and skill sets. While the course content of some span over 20 hours, others are some 50 hours long. The course is taught over several classes and each class enables the rural populace to get familiar with computer basics. These packages have proved to be extremely popular in rural areas, as they are seen as means to towards employment. 
Remote tutorials: The online tutorial is specifically focused on assisting children complete their school examinations. Unfortunately, there aren't too many good teachers at the village level and the remote tutorial attempts to bridge this gap through three modes - learn, practice and test. The remote tutorial is based on a question and answer format. It looks at questions from past papers and suggests the kind of answers that need to be provided. Each module is supplemented with a voice-over that makes learning easy. The online tutorial has focused on several subjects, including Mathematics, Social Science, English and Science.

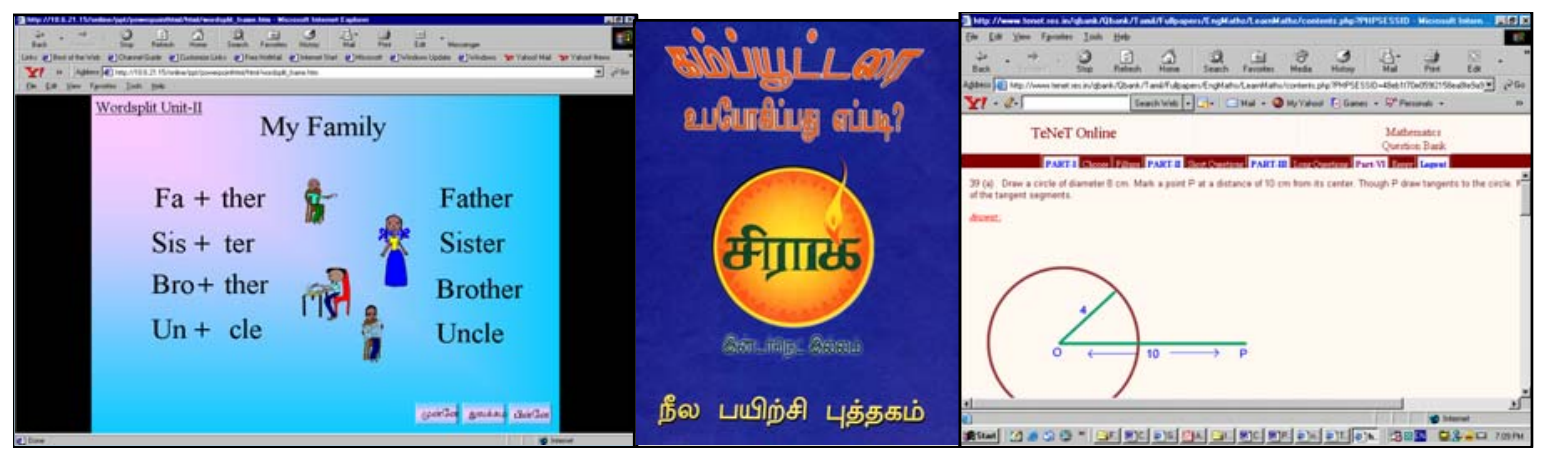

Fig 1: Spoken English, Computer education and Tutorials

Spoken English: Villagers view Spoken English as an important credential in acquiring a job. Having understood this significance, Spoken English module has been specially created to help children and adults improve their English speaking ability.

\section{Typing:}

Several children come to the kiosk to learn basic typing. They pay a dollar a month and attend 810 classes for this purpose. Similarly, adults avail themselves of the kiosk's facilities to acquire typing skills, which they again find is useful in obtaining employment. Apart from this, villagers also may get their resumes made.

\section{Photography:}

Most kiosks double as photography studios, where photographs are shot using a digital camera and a printout can be made available. Photography is proving to be a major source of income. Photographs for a variety of purposes, including for government forms and veterinary applications, are being shot at the kiosk.

\section{Others:}

Children make greeting cards using the computer, which is surprising considering that their knowledge about computers is only some six months old.

\section{Agriculture Consultancy and Veterinary:}

Farmers in the village bring their animals to the kiosk and get them treated by doctors remotely. A videoconference is initiated between the farmer and the doctor. Conferences are also welcomed among farmers. Through such conferences, queries, doubts and apprehensions get resolved. These services are extremely important to the rural people as their livelihood depends on agriculture and cattle/poultry. 


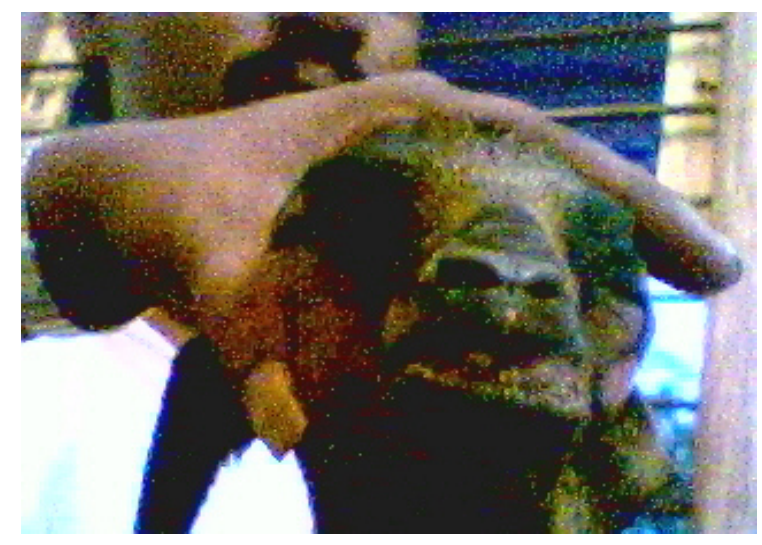

Fig 2. Farmer with his goat at a village

A current example is the case of the farmers of $\mathrm{T}$ Ulagapichampatti. Their okra produce was turning yellow. A videoconference between the farmer and agriculture specialists, in the city, was set up. The leaves and the produce of the damaged crop were shown through the web-cam, the kind and amount of fertilizers added was also discussed. The experts diagnosed it to be yellow mosaic. Appropriate treatment was administered and the farmers were able to prevent a loss of Rs $1,40,000$.

nLogue is also planning to enhance the services provided to the farmers through videoconferencing by accessing a greater number of resources and through additional services like weather reports, crop price and other market related information.

\section{Health Care:}

Even though Public Health Centres exist in every three to four villages, many of these centres function rather poorly. Health care is a major concern in rural areas. Qualified doctors in reasonable numbers are available only in towns.

In May 2002, an enterprising kiosk operator took the initiative to send some pictures of an elderly woman's eyes to n-Logue. The lady was suffering from severe eye pain. The pictures were forwarded to doctors in the Aravind Eye Hospital (Fig 3), a large facility in a neighbouring city. The doctors used Internet-based video-conferencing to examine the patient. This provided the basis for a program of video-conferencing based eye-care for rural areas. Eye-doctors in town now regularly examine the eyes of patients in the villages by means of video and suggest remedies as might be required. 


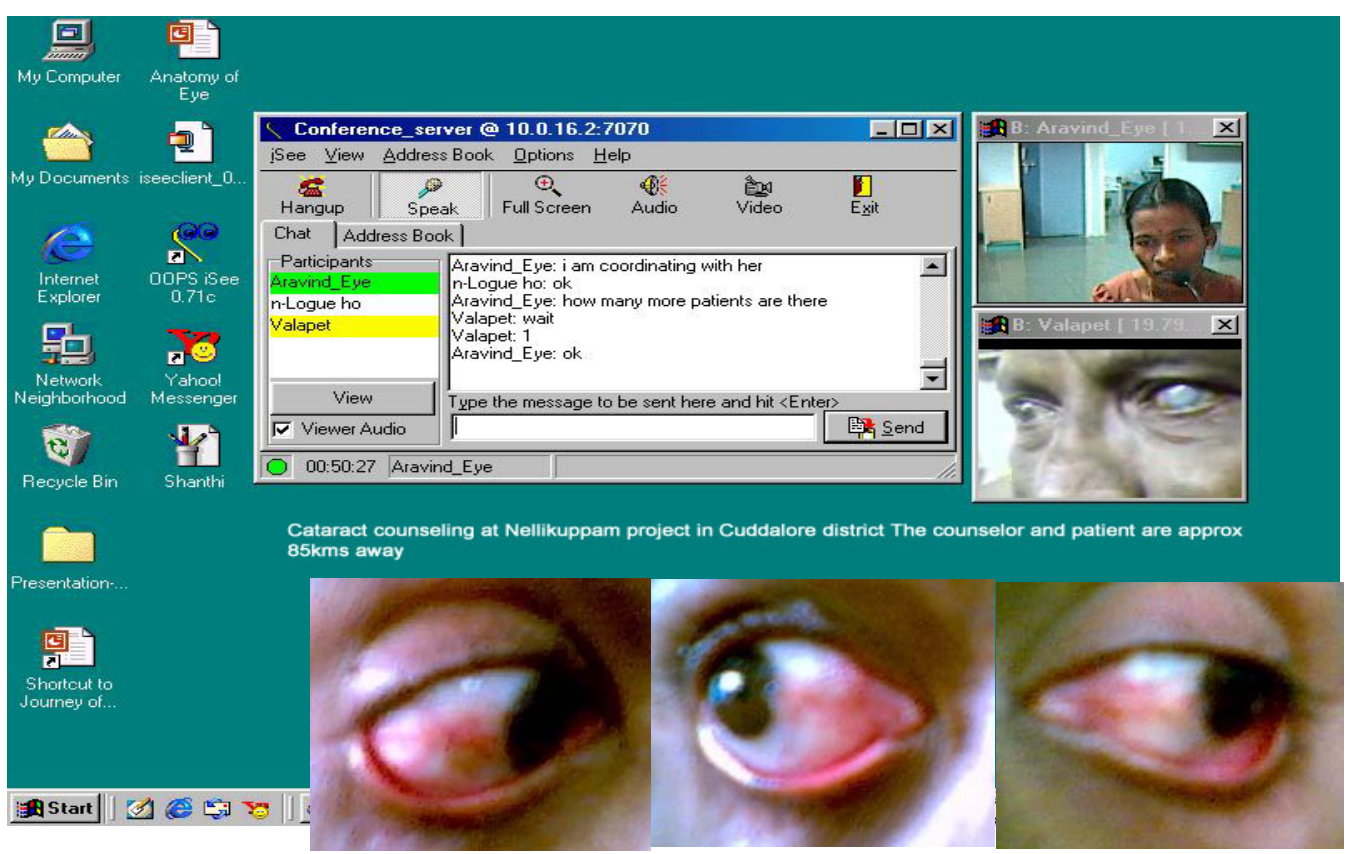

Fig 3. Remote Eye Care consultation with Aravind Eye Hospital

This process was quickly extended to regular health care. Doctors in towns use video-conferencing to provide medical advice to remote patients located in villages. A multi-party video-conferencing product is commonly used, where multiple villages are simultaneously connected to a doctor in the town. The doctor connects to several villages at the same time and examines them in full public view. Questions of privacy have been raised on account of such a procedure. However, most villagers prefer this mode of examination, and when asked, one remarked that such a system makes the doctors more accountable.

\section{e-governance:}

Similarly, the Internet is being used to approach the government for all kinds of problems. There is a well-known story concerning a handicapped person who sent a complaint to the Chief Minster's cell complaining of unfair termination of service. Having received the complaint, swift action was initiated wherein, the person in question was handed back his job.

Other e-government services including widow's pensions, and birth, death and land certificates have been applied for through the Internet.

While this service has worked commendably well in certain villages, it has failed to make a dent in several others. The performance of such a service depends on the district collector, who needs to drive the service.

For instance, in Thiruvallur, a small town on the outskirts of Chennai, the district collector started what is popularly known as a 'weekly web darbar' with the villagers. Through the darbar, the collector connects to 50 villages simultaneously. Through these sessions, he answers queries and addresses grievances.

\section{Entertainment:}

There are several means of entertainment like Chiraag radio and movie CDs that are played at the kiosk. Recently, a newspaper, entirely written and prepared by the villagers, was launched.

\section{Other Benefits:}


The KO has also donned the task of a data collector. Data pertaining to land holding/number of families/ animals/ water/ source of income/ income levels/ educational qualification have been gathered. This data can be useful to several corporations and agencies across the country.

\section{Technologies Supporting Kiosk Operations}

One question that has been asked several times is - how has all this been done? What has made nLogue capable of delivering such services? Today, n-Logue is present in over 40 districts. The TeNeT Group has worked with the vision of providing significant services in rural India. It has incubated over 14 companies with over 1400 engineers whose focus has solely been developing technology for rural areas. Such an approach has been purposely initiated because if programs are directed towards developing technology for urban areas, this tends to completely absorb efforts and rural areas are generally forgotten.

\section{Language Applications:}

While connectivity was easily addressed, how were rural people to communicate if they had no knowledge of English, the lingua franca of the Internet? It was also found that existing language software was quite expensive to be installed at the village kiosk. TeNeT found an answer in CKShakti, an office suite package in the local language from a venture called Chennai Kavigal Private Ltd, which it helped create. CKShakti offers most of the features offered by Microsoft and costs a fraction of the cost of the MS Office package. It also has a dual language option, which facilitates switching between the local language and English. CKShakti is available in three dual language packages as well as in English.

\section{Video-conferencing Software:}

Initial studies at the Internet kiosks indicated that a lot of rural subjects still regarded email as a difficult communication medium and needed the help of the kiosk operator to type and also read out messages to them. Hence most applications such as telemedicine, education, and agriconsultancy were difficult for them to use. To address this problem, TeNeT with a related company, Objective Oriented Programming Systems Pvt. Ltd (OOPS) created video-conferencing software called iSEE which can function at very low bandwidth. When this video-conferencing software was installed in the kiosks it facilitated the use of health, education and consulting services as the villagers were more comfortable having a face-to-face interaction with the respective experts.

\section{Remote Diagnostics:}

The doctors who regularly use the Internet to deliver healthcare services to the rural poor, have often wondered whether they might be able to do a much better job if they could remotely monitor the patient's temperature, blood pressure and heart beats.

Recently Neuro-synaptic Ltd, with help from the TeNeT group, has launched an interesting lowcost remote diagnostic kit. The kit is placed in the kiosk and enables a doctor to measure the temperature, blood pressure, pulse count and ECG of the patient remotely and also to listen to heartbeats using a remote stethoscope. This combined with video-conferencing enables a doctor to significantly enhance remote medical treatment. The kit is being incubated in several kiosks by nlogue.

\section{The Rural ATM - A New Technology:}

TeNeT believes that going beyond normal Internet applications and leveraging ICT to enhance livelihoods would be the primary means of sustaining rural kiosks. One of the innovative applications it developed to support livelihood is a rural automatic teller machine (ATM).

With the support of the TeNeT group at IIT, Madras, Vortex Engineering Ltd. has developed a low cost ATM specifically for rural applications. The ATM will make use of an existing network 
of Internet kiosks that currently access hundreds of villages in India. Capable of dispensing both new and used notes, the ATMs will also offer non-cash transactions, micro-deposits, credit and a number of other services tailor-made for rural areas. The machine can be used with ATMs or SmartCards and also has the option of using fingerprint identification. The machine costs around US\$1,000, just a fraction of the US\$20,000 it takes to install an urban ATM.

\section{The Future:}

Where does one go from here? We believe in the existence of a good business model and technology to take Internet to all villages in India. Through this, services like health and education can be driven. Apart from these basic services, livelihoods have to be enabled. Enough needs to be done to help the rural populace generate wealth. Towards that end, one needs to create viable rural micro-enterprises in rural areas, in the domains of agriculture, food processing, animal husbandry, handicrafts and IT-based services among others. How can Internet help in this regard?

There are the four pillars on which a successful micro enterprise rests:

- Finance

- Knowledge, training and support

- Buying/selling/logistics

- Risk sharing ability

If viable micro-enterprises can be set-up in villages, one can significantly impact the rural economy. Today, the TeNeT Group dreams of doubling rural GDP. It is hoped that the per capita rural GDP of India will double from its current figure of $\$ 200$ to $\$ 400$. After all, the kiosk is not just a communication centre. It has the ability to become a communication hub, with a base station, 50 telephone and Internet connections. It has the potential to become a virtual university, training centre, banking outlet, trading outlet, agriculture support centre and much more. The key is to dream and to make it happen. 